\title{
A SINTAXE VISUAL NO DESIGN DE INTERFACE DO BOOK APP INFANTIL TREASURE KAI AND THE LOST GOLD SHARK ISLAND
}

\author{
Deglaucy Jorge Teixeira \\ Universidade Federal de Santa Catarina - UFSC \\ deglaucyjorge@gmail.com \\ Juliane Vargas Nunes \\ Universidade Federal de Santa Catarina - UFSC \\ julivn@gmail.com \\ Berenice S. Gonçalves \\ Universidade Federal de Santa Catarina - UFSC \\ berenice@cce.ufsc.br \\ Richard Perassi Luiz de Sousa \\ Universidade Federal de Santa Catarina - UFSC \\ richard.perassi@uol.com.br
}

Resumo: O livro infantil ilustrado apresentado em suportes digitais, como tablets e e-readers, permite o incremento de recursos interativos, elementos dinâmicos e estímulos sonoros que o transformam em um produto hipermídia. Este artigo, entretanto, apresenta um estudo descritivo-analítico que, especificamente, trata da estrutura gráfico-visual do ebook infantil Treasure Kai and the Lost Gold Shark Island. Considera-se a sintaxe visual do produto, descrevendo o arranjo dos elementos visuais básicos junto aos princípios de design como estratégia de comunicação na interface gráfica. Tais questões definem a organização visual da publicação, que deve ser legível para interface e coerente com o sentido geral da mensagem. Com base neste estudo, identificou-se estratégias utilizadas para definira estrutura gráfico-visual do ebook infantil. Dentre elas destacase as características formais, cor e texturas utilizadas para diferenciar os objetos interativos, tratamentos específicos em planos de fundo para enfatizar ou indicar as mudanças ocorridas no fluxo da história e contrastes que contribuem para percepção dos elementos e indicar hierarquias no processo de leitura.

Palavras-chave: Livro Infantil ilustrado, Book app infantil, Sintaxe Visual.

Abstract: The children's picturebook presented in digital media, such as tablets and e-readers, allows the growth of interactive features, dynamic elements and sound stimuli that make it a hypermedia product. This paper, however, presents a descriptive-analytical study that specifically addresses 
the visual graph structure of child ebook Treasure Kai and the Lost Gold Shark Island. The visual grammar of the product is considered, describing the basic arrangement of visual elements in the principles of design as a communication strategy in the graphical interface. Such questions define the visual organization of the publication, which should be readable and coherent interface with the general meaning of the message. Based on this study, was identified strategies used will define visual graph structure of child ebook. Among them stands out the formal characteristics, color and textures used to differentiate interactive objects, specific treatments backgrounds to emphasize or indicate the changes in the flow of history and contrasts that contribute to the perception of the elements and display hierarchies in the process reading.

Keywords: Children's picturebook, Children's book app, visual grammar.

\section{INTRODUÇÃO}

O ebook Treasure Kai and the Lost Gold Shark Island é um exemplo de última geração dos produtos editoriais decorrentes da evolução tecnológica que permitiu o surgimento e a difusão dos livros digitais. Atualmente, com a popularização dos dispositivos digitais os livros eletrônicos (ebooks) têm sido projetados para serem lidos em smartphones, e-readers e tablets. Além das ferramentas hipermidiáticas já utilizadas em computador pessoal, os ebooks para dispositivos portáteis podem lançar mão da manipulação direta e gestos na interação do leitor a partir de uma tela touch screen. Porém, um projeto voltado para dispositivos portáteis, requer a adequação do formato gráfico para um layout em mídia digital, envolvendo o planejamento da sintaxe visual em termos de dimensão, orientação, resolução, dentre outras questões para efetivar a mensagem.

Assim, este artigo apresenta um estudo descritivo-analítico sobre a estrutura gráfico-visual do ebook infantil Treasure Kai and the Lost Gold Shark Island, que tem como suporte o iPad (tablet da Apple), buscando compreender a relevância da escolha, tratamento e organização dos elementos visuais em sua interface. Por meio deste estudo pretende-se identificar estratégias na definição da estrutura gráficovisual de um ebook infantil que possam promover a compreensão do texto e a leitura interativa no ambiente digital.

\section{LIVRO INFANTIL ILUSTRADO}

Os tipos de livros infantis são classificados segundo Linden (2011) de acordo com a disposição interna do conteúdo: livros com ilustração, primeiras leituras, livros ilustrados, histórias em quadrinhos (HQ), livros pop-up, livros-brinquedo, livros interativos e livros imaginativos.

O livro infantil ilustrado é a obra literária direcionada para crianças onde a imagem predomina e onde a narrativa é articulada entre texto e imagem, podendo apresentar-se em vários gêneros e suportes (LINDEN, 2011).

Os tipos de livros infantis podem assumir diferentes materialidades, que interferem na compreensão do mesmo, como livro cartonado, de plástico, livro-CD e atualmente o ebook. A obra pode ainda diferenciar-se em gêneros como contos, poesia, histórias policiais, documentários etc (LINDEN, 2011). 
As inovações relacionadas à sua materialidade ampliam a concepção tradicional do livro como objeto. Para Linden (2011) a materialidade do livro infantil ilustrado não desvia seus princípios de funcionamento, desde que tenha sido bem planejado na fase de concepção, embora possa enriquecer ou limitar suas possibilidades expressivas.

\subsection{Book app infantil}

Diferente do livro impresso que é ao mesmo tempo o suporte e conteúdo do livro, o formato digital necessita de um mecanismo físico - o hardware, que pode ser um computador pessoal, um smartphone, um tablet ou um e-reader; de um leitor de arquivo - um software de leitura para abrir o arquivo; e o livro propriamente dito - 0 arquivo ebook (SPALDING, 2012).

Assim como um arquivo de texto (doc ou txt) precisa do software word para acessá-lo, os ebooks necessitam de dispositivos específicos e software compatível para cada formato de arquivo.

De acordo com Duarte (2010), ebook é um termo genérico, podendo existir vários formatos de arquivo nesta categoria como PDF, ePub, AZM e APP. O formato aplicativo (book app), por se tratar de um software executável, destaca-se dos demais por apresentar maior possibilidade interativa e não necessitar de outro software para acessá-lo.

Neste contexto, o book app infantil consiste em um livro infantil ilustrado no formato de aplicativo. Segundo Teixeira et al (2013, p.4) "no book app infantil a ilustração é mais um recurso do texto não verbal dentro do ambiente hipermidiático que assume sua importância como integrante do texto verbal". Assim, um book app infantil bem sucedido deve preencher os requisitos de um livro infantil ilustrado tradicional, mas com o potencial extra, permitido pelo ambiente digital (BIRCHER, 2012).

\subsection{Design do livro infantil ilustrado}

Quando texto e imagem estão magistralmente combinados o livro ilustrado funciona como uma unidade e desta forma sua concepção é feita em um único design (CULLINAN et al, 2014). A combinação da arte verbal e visual é mais complexa do que um trabalho artístico, pois funciona como uma parte vital de um trabalho literário, onde frequentemente informações e significados não presentes no texto são adicionados por meio da linguagem visual para criar história dentro da história.

O design do livro infantil ilustrado envolve mídias, técnicas e estilos. O meio de produção está relacionado ao material utilizado como lápis, tinta, papel, computador, dentre outros. A técnica pode envolver pintura, gravura, colagem, fotografia etc. Ao combinar o meio com a técnica e outras escolhas estéticas, o designer estabelece um estilo próprio que expressa o tema, transmite informações, explica o conceito e ambienta a história (CULLINAN et al, 2014).

Esta composição visual deve ser organizada na página a fim de compor o projeto do livro. Esta estruturação é feita com os elementos básicos da arte: ponto, linha, plano, mancha, formas e texturas. E com os princípios de design: ritmo, equilíbrio, variedade, ênfase, ordem espacial e unidade, a fim de unificar o conteúdo para transmitir significado (CULLINAN et al, 2014).

\section{SINTAXE VISUAL}


De acordo com Dondis (2003) existem linhas gerais para criação e composição visual. Apesar das diferenças culturais há um sistema visual perceptível a todos os seres humanos capaz de organizar elementos gráfico-visuais para facilitar a compreensão da mensagem por meio de uma sintaxe visual. São eles: ponto, linha, forma, plano, tom, cor, textura, escala ou proporção, dimensão e movimento.

\subsection{Elementos gráfico visuais}

Para este estudo selecionou-se nove elementos gráfico-visuais cuja reunião e ordenação podem compor a representação das coisas visualmente percebidas, sendo eles: ponto, linha, plano, mancha, forma, cor, textura, espaço e volume.

De acordo com sua dimensão, posição e relação com os elementos que o circundam o ponto pode destacar-se ou misturar-se à massa. Assim, uma série de pontos pode formar uma linha, uma massa de pontos pode tornar-se uma textura, forma ou plano. A linha exerce funções de demarcação espacial e configuração, expressando formas e figuras e delimitando a união entre dois planos. Quando atinge certa espessura, a linha torna-se um plano; e quando multiplicada pode gerar também volumes e texturas.

$\mathrm{Na}$ representação bidimensional o plano é considerado e representado como uma mancha uniforme, na qual não se percebe variações cromáticas ou tonais. Um plano com limites definidos consiste em uma forma. Já a mancha é o elemento determinante da linguagem pictórica ou fotográfica, porque apresenta variações cromáticas e tonais. Sobre esses elementos gráfico-expressivos atuam aspectos que os qualificam, como cor, textura, espaço e volume.

A cor é a qualidade mais rapidamente assimilada pelo observador, apreendida antes mesmo da forma. As cores possuem significados, que são transferidos para a forma a qual é aplicada. Atuando de forma associada a cor, a textura é a qualidade tátil da superfície dos objetos, percebida a partir do contato das mãos, mas também da visão. As texturas exploram qualidades como áspero ou liso, firme ou esponjoso, irregular ou liso. Também simulam materiais e técnicas como nas texturas com pinceladas aparentes, traços a lápis ou carvão.

O espaço atrai a atenção do espectador para os objetos na página e pode criar a ilusão de distância. A falta de espaço pode gerar desconforto, confusão e caos. O uso generoso de espaço sugere serenidade, mas também pode significar vazio, solidão e isolamento. A representação de volume no plano bidimensional se utiliza de convenções gráficas, dentre elas, a perspectiva (LUPTON, 2008).

A partir desses elementos, o design cria imagens, ícones, padrões e tipografias, com os quais compõem as mensagens visuais (LUPTON, 2008). Dentro do campo das mídias digitais interativas, o Design se volta para as relações estabelecidas entre usuário e sistema durante a realização das tarefas. Assim, pode facilitar a recepção e interpretação de dados e informações, contribuindo para a transmissão eficiente de conteúdos (NUNES, GONÇALVES, 2013).

\subsection{Princípios de Design}

Os princípios de design são regras e conceitos para organizar e otimizar os elementos gráfico-visuais em um plano bidimensional, assim como uma receita combina seus ingredientes. Os princípios de design podem ser divididos em três categorias: Unificação, Ênfase e Força de percepção (COSTELO et al, 2012). 


\subsubsection{Unificação}

Quando as informações estão organizadas sem critério ou simplesmente desorganizadas o cérebro trabalha mais para encontrar um significado. Mas quando o conteúdo é organizado conforme os princípios de design, o cérebro pode trabalhar mais rápido e a comunicação será mais efetiva (COSTELO et al, 2012). O princípio de Unificação inclui Proximidade, Alinhamento, Similaridade e Repetição.

Proximidade: É mais provável que se entenda a relação entre os objetos quando eles estão juntos. Como usar título próximo da imagem a que se refere. Geralmente a proximidade é usada com espaço brando para manter o grupo de objetos mais perceptível.

Alinhamento: O princípio do alinhamento posiciona os objetos juntos a uma aresta ou linha. Em uma página ou múltiplas páginas, o alinhamento deve ter consistência e facilitar a leitura. Não é recomendado variar os tipos de alinhamento (COSTELO et al, 2012).

Similaridade: 0 cérebro percebe o relacionamento em um grupo de objetos visuais a partir da semelhança ou uniformidade do estilo de seus atributos.

Repetição: Está diretamente ligada a similaridade, pois sugere repetições de elementos gráfico-visuais como linha, cor, forma, e textura em diferentes objetos para fortalecer a unidade visual.

\subsection{2 Ênfase}

O princípio da Ênfase deve destacar o centro ou ponto de interesse principal. Em um jornal, por exemplo, a frase escrita em caracteres de maior tamanho é projetada para chamar a atenção do leitor para o que se acredita ser a notícia mais importante do dia.

A Ênfase pode ser usada como um guia rápido de navegação em uma mídia digital. A variação de tamanho dos elementos no espaço visual é uma das formas mais comuns de enfatizar uma informação, entretanto existem outras formas que podem ser exploradas como Contraste, Cor, Profundidade e Proporção (COSTELO et al, 2012).

Contraste: de acordo com Gomes filho (2000), o contraste é uma contra-força à tendência do equilíbrio absoluto e tem a função de estimular e atrair a atenção. $O$ contraste pode estar relacionado a diferença cromática, como o texto preto em um fundo branco que se mostra como o melhor contraste para leitura.

Cor: a cor também atua como princípio de design. Segundo Costelo et al (2012), a cor é a mais poderosa ferramenta para gerar contraste e enfatizar objetos no espaço visual. Um ponto de cor, por exemplo, pode rapidamente direcionar o foco da visão, principalmente se utilizar cores quentes, mais atrativas ao olho humano. Mas deve-se evitar o uso exagerado deste recurso para não causar opressão ao leitor.

Profundidade: a profundidade está relacionada com o princípio de percepção figura-fundo. Largamente utilizada nos objetos visuais por meio de sombras, luzes, perspectivas e outros efeitos para simular uma aparência de profundidade.

Proporção: é a escala relativa de um objeto visual comparado a outro em uma composição.

\subsubsection{Força de percepção}


Quando o leitor olha para uma representação gráfica em uma tela, seu cérebro recebe constantes impulsos de atração dentro do espaço visual. Independentemente de ver uma fotografia em cima de uma mesa ou em um quadro na parede, tende-se a perceber um direcionamento da parte cima para baixo. Mas esta percepção não está ligada ao campo gravitacional e sim a força do campo visual que pode direcionar a leitura. Espaços brancos podem funcionar como espaços de respiro em volta dos objetos visuais e até neutralizar a força visual da tela. Os princípios ligados à experiência de força de percepção são Equilíbrio, Continuidade, Figura-fundo e Fechamento psicológico (COSTELO et al, 2012).

Equilíbrio: Acontece quando o peso visual dos objetos está bem distribuído na composição. O senso de equilíbrio pode ser alcançado por meio da escala, cor ou posição dos objetos no espaço visual de forma simétrica, quando ambos os lados do espaço estão opostos e equivalentes, ou assimétrica, quando a equivalência é estabelecida por objetos de diferentes tamanhos, cor e tom.

Continuidade: Neste princípio o cérebro tende a processar o que se vê em uma linha contínua e previsível livre de obstáculos e de mudança de direção.

Figura-fundo: Na psicologia da Gestalt, um elemento que é percebido em primeiro plano é denominado figura e o que fica por trás, fundo.

Fechamento psicológico: Acontece quando as informações parciais são completadas mentalmente.

\section{PROCEDIMENTOS METODOLÓGICOS}

Como objeto da análise foi definido o book app infantil Treasure Kai and the Lost Gold Shark Island, que se destaca por sua lista de premiações, além de ser aprovado com o selo QED (Quality, Excellence, Design) e ser um dos 20 book apps ganhadores de 5 estrelas pelo prêmio da Digital Storytime 2012.

Buscando viabilizar a análise, foram selecionadas e capturadas, na forma de imagens estáticas, algumas de suas telas. Posteriormente, essas telas foram analisadas a partir de sete elementos gráfico-visuais pré-definidos a partir da literatura: linha, forma, plano, cor, textura, espaço e volume, no atendimento de três princípios de design: Unificação, Ênfase e Força perceptual. Os elementos gráfico-visuais ponto e mancha não foram analisados individualmente por estarem associada aos demais, nas telas selecionadas. Por fim, os dados da análise foram discutidos, dando origem a considerações sobre a estrutura gráfico-visual no design de um ebook infantil no formato book app.

\section{DISCUSSÃO}

Para esta análise foram selecionadas quatro telas do book app Treasure Kai and the Lost Gold Shark Island de acordo com os diferentes contextos e ambientações da história.

Treasure Kai and the Lost Gold Shark Island é um book app da empresa Treasure Bound Books Pty Ltd produzido para iPad, indicado para crianças de 4 a 9 anos, texto de autoria de Karen Guinn Robertson e ilustrado por Victor Guisa

Este book app conta uma história de aventura sobre um menino chamado Kai que sonha em encontrar um tesouro perdido.

Seu conteúdo é composto por ilustrações, animações, trilha sonora, caixas de texto, sons interativos e narração. Sua navegação é linear e oferece, a partir de um 
determinado ponto da narrativa, oito trajetórias possíveis por meio de links representados por imagens de baús. Em todas as telas a narrativa é apresentada na forma de texto e áudio. Os comandos de controle do áudio são oferecidos junto ao texto dentro de uma caixa de diálogo, que pode ser deslocada pelo usuário para qualquer lugar da tela com um gesto de arrastar.

Também são disponibilizados outros recursos de interação como o ícone para retorno a tela inicial, presente em todas as telas, e textos e objetos nos quais o usuário precisa clicar para avançar a narrativa.

A primeira tela (Fig. 1) corresponde ao início da narrativa, onde o protagonista, Kai, apresenta sua história ao leitor por meio de narração e uma caixa de diálogo que o texto vai se destacando à medida que as palavras estão sendo faladas.

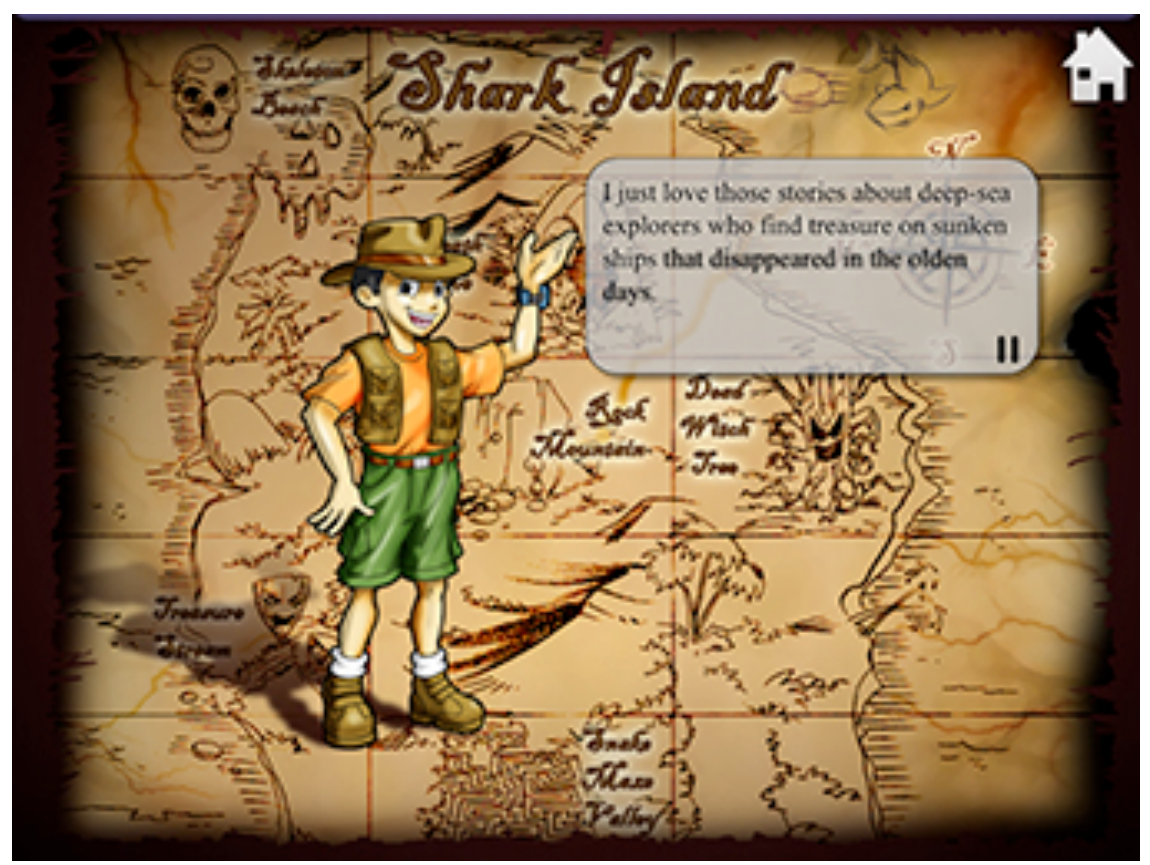

Figura 1 - Tela de apresentação da história pelo protagonista, Kai.

Fonte: Book app Treasure Kai and the Lost Gold Shark Island.

A segunda tela (Fig. 2) mostra o ambiente preferido do personagem, a loja de seus pais, com vários objetos interativos que quando clicados emitem seu som característico, como uma vitrola que toca música ou um avião que faz barulho de turbina. O texto segue o padrão da caixa de diálogo. 


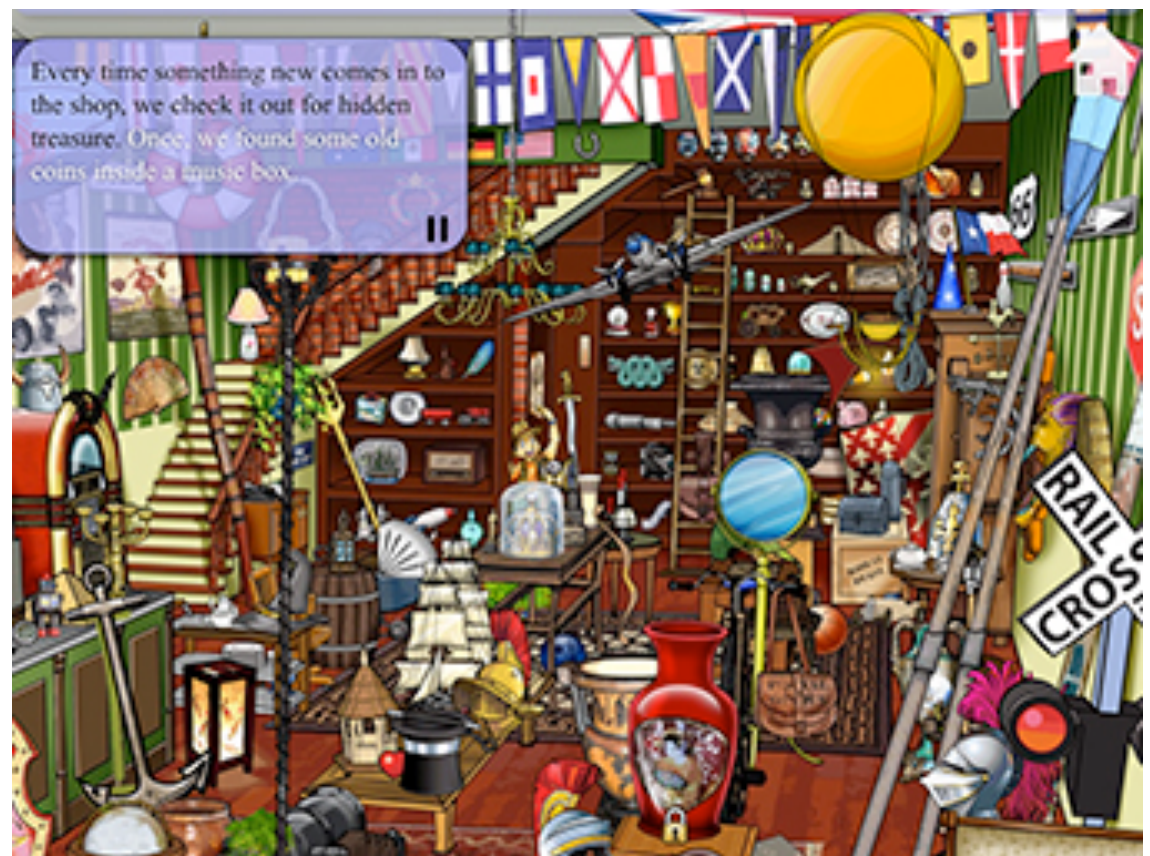

Figura 2 - Ambiente preferido de Kai, a loja de seu pai.

Fonte: Book app Treasure Kai and the Lost Gold Shark Island.

A terceira tela (Fig. 3), além da caixa de texto, mostra as opções de trajetória de leitura com uma animação nos baús na base da tela. A cada interação os baús são embaralhados para o leitor interagir e optar por um deles.

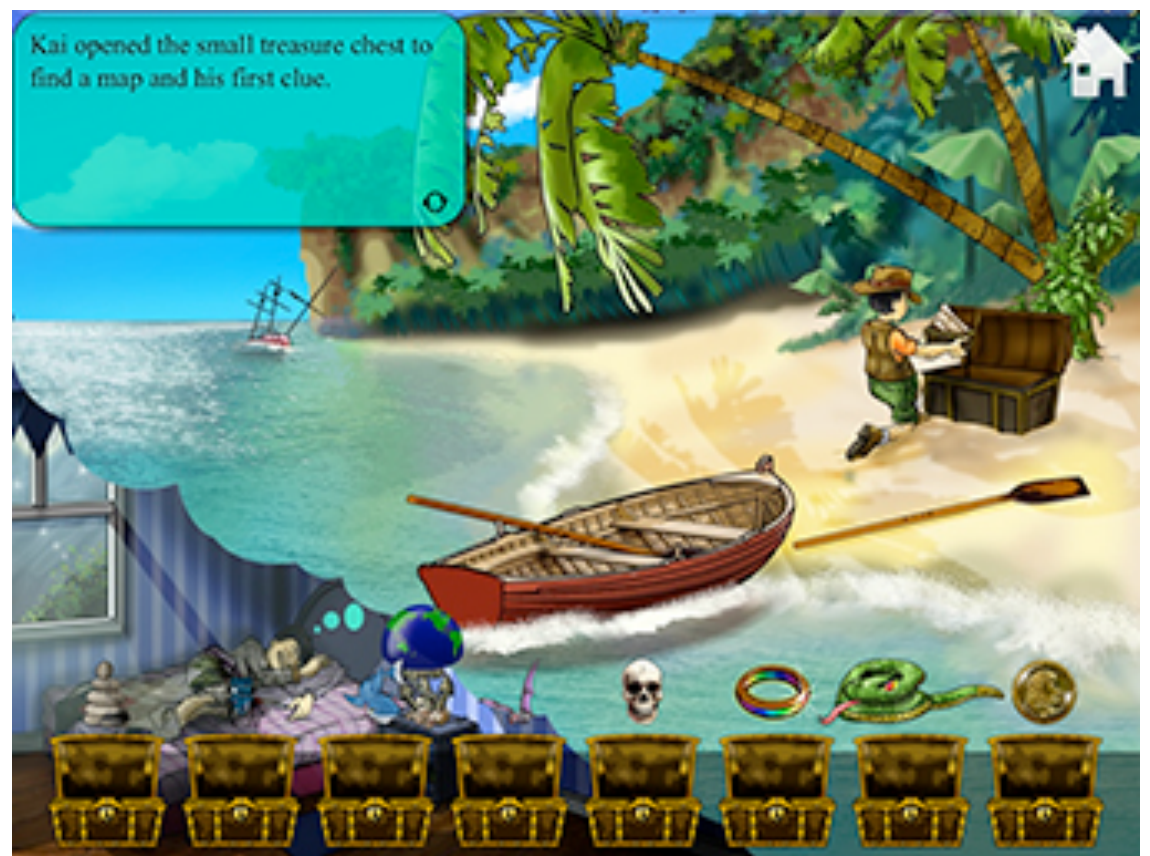

Figura 3 - Opções de trajetórias por meio de interatividade nos baús.

Fonte: Book app Treasure Kai and the Lost Gold Shark Island.

A quarta tela (Fig. 4) mostra o resultado de uma das trajetórias escolhidas, chuva de pedras. Esta tela se diferencia das telas de narrativa anterior por apresentar um texto instrucional narrado fora da caixa de diálogo. 


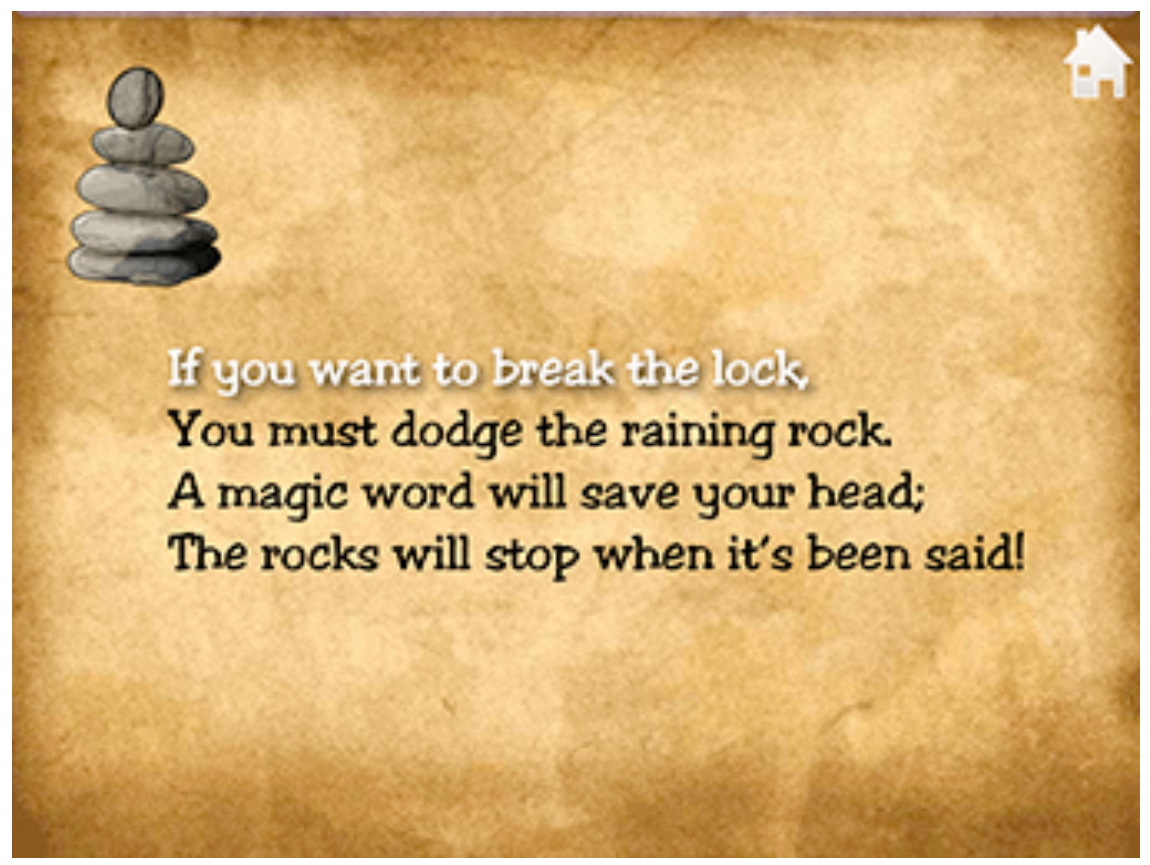

Figura 4 - Tela com um dos resultados escolhidos pelo leitor.

Fonte: Book app Treasure Kai and the Lost Gold Shark Island.

Na sequência é apresentado um quadro que contém os dados da análise das telas anteriormente apresentadas, realizada a partir de sete elementos gráfico-visuais: linha, forma, plano, cor, textura, espaço e volume (dispostos na coluna da esquerda), os quais se cruzam com três grupos de princípios de design: unificação, ênfase e força de percepção (dispostos na primeira linha).

Quadro 1 - Relação dos elementos gráfico-visuais e os princípios de design.

\begin{tabular}{|c|c|c|c|}
\hline & Unificação & Ênfase & Força de Percepção \\
\hline & $\begin{array}{l}\text { A linha é utilizada em todas as } \\
\text { figuras como contorno, } \\
\text { tornando-as semelhantes e } \\
\text { gerando repetição. Além de } \\
\text { delimitar os planos nas } \\
\text { ilustrações e nos objetos } \\
\text { interativos. }\end{array}$ & $\begin{array}{l}\text { Em alguns momentos existem } \\
\text { contraste de espessura, como nos } \\
\text { bolsos do colete e da bermuda do } \\
\text { personagem na Fig. } 1 \text {. Porém, nem } \\
\text { sempre fica claro seu critério de } \\
\text { variação como, por exemplo, na } \\
\text { Fig. } 2 \text { em que a âncora localizada } \\
\text { no canto inferior esquerdo da } \\
\text { imagem, mesmo estando em } \\
\text { mesmo plano, possui um traço com } \\
\text { espessura diferente do móvel em } \\
\text { que está apoiada. }\end{array}$ & $\begin{array}{l}\text { A linha utilizada como } \\
\text { contorno das figuras torna } \\
\text { explícitos seus limites e as } \\
\text { separa dos demais } \\
\text { elementos. Contudo, em } \\
\text { alguns casos, a semelhança } \\
\text { no tratamento das linhas } \\
\text { dificulta a diferenciação } \\
\text { entre figura e fundo, como } \\
\text { podemos visualizar na Fig. } 2 \text {. }\end{array}$ \\
\hline
\end{tabular}




\begin{tabular}{|c|c|c|c|}
\hline 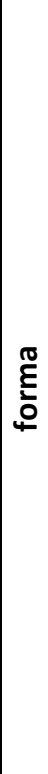 & $\begin{array}{l}\text { Todas as formas utilizadas nas } \\
\text { ilustrações são complexas, } \\
\text { com elevado nível de } \\
\text { detalhamento e de pequena } \\
\text { dimensão. Assim, em alguns } \\
\text { casos fica difícil apreendê-las } \\
\text { individualmente. Na Fig. 2, por } \\
\text { exemplo, objetos interativos } \\
\text { possuem o mesmo } \\
\text { tratamento que os demais } \\
\text { objetos. Por outro lado, na } \\
\text { Fig. } 3 \text { os baús formam uma } \\
\text { unidade claramente distinta, } \\
\text { devido a similaridade, } \\
\text { proximidade, alinhamento e } \\
\text { repetição de seus elementos, } \\
\text { o que facilita a identificação } \\
\text { de sua qualidade interativa. }\end{array}$ & $\begin{array}{l}\text { Em contraponto às formas } \\
\text { aplicadas às ilustrações, as caixas } \\
\text { de diálogo utilizam uma figura } \\
\text { simples - um retângulo com os } \\
\text { cantos chanfrados, destacando-se } \\
\text { das demais formas. Na Fig. } 2 \text { são } \\
\text { utilizadas formas mais geométricas, } \\
\text { em consonância com o caráter } \\
\text { sintético (não natural) da cidade; } \\
\text { ao contrário das figuras } 1 \text { e } 3 \text { que } \\
\text { utilizam formas mais orgânicas para } \\
\text { enfatizar o caráter natural das } \\
\text { paisagens que representam. }\end{array}$ & $\begin{array}{l}\text { Nas ilustrações é perceptível } \\
\text { a relação entre figura e } \\
\text { fundo, exceto na Fig. } 3 \text { em } \\
\text { que as formas se misturam } \\
\text { devido à sua semelhança. } \\
\text { O uso de fontes de famílias e } \\
\text { tamanhos diferentes } \\
\text { evidencia uma hierarquia da } \\
\text { informação, onde os textos } \\
\text { de diálogo, voltados para a } \\
\text { interação (Fig. 4), se } \\
\text { destacam dos textos da } \\
\text { narrativa (Fig. 1, } 2 \text { e 3). }\end{array}$ \\
\hline$\frac{0}{\frac{0}{0}}$ & $\begin{array}{l}\text { É possível identificar a } \\
\text { repetição de elementos } \\
\text { dentro do plano, como o } \\
\text { ícone de retorno a tela inicial } \\
\text { localizado no canto superior } \\
\text { esquerdo, e as caixas de texto } \\
\text { sobre as ilustrações. }\end{array}$ & $\begin{array}{l}\text { Na Fig. } 1 \text { é perceptível um } \\
\text { tratamento diferenciado das } \\
\text { margens do plano, que } \\
\text { representam uma espécie de } \\
\text { moldura que remete a leitura do } \\
\text { mapa do tesouro, em outro } \\
\text { ambiente. }\end{array}$ & $\begin{array}{l}\text { A diferença de dimensão } \\
\text { entre as duas imagens na } \\
\text { Fig. } 3 \text { torna a ilustração } \\
\text { desequilibrada, observado } \\
\text { pelo fato da imagem de } \\
\text { maior dimensão se } \\
\text { encontrar na parte superior. }\end{array}$ \\
\hline ̀̀ & $\begin{array}{l}\text { Para adaptarem-se ao cenário, } \\
\text { as caixas de texto mudam de } \\
\text { cor, o que compromete a } \\
\text { unidade visual entre as telas. } \\
\text { Já na tipografia existe um } \\
\text { padrão cromático, no qual o } \\
\text { trecho do texto que está } \\
\text { sincronizado com o áudio } \\
\text { muda na cor preta para a } \\
\text { branca, exceto na Fig. 1, em } \\
\text { que sofre o acréscimo de uma } \\
\text { sombra, ao invés de mudar de } \\
\text { cor. }\end{array}$ & $\begin{array}{l}\text { O ebook utiliza uma ampla paleta } \\
\text { de cores, quase sempre divididas } \\
\text { em duas escalas bem definidas: } \\
\text { cores frias e cores quentes. Nas } \\
\text { figuras } 1,3 \text { e } 4 \text { fica evidente a } \\
\text { predominância de uma dessas } \\
\text { escalas. } \\
\text { Ao contrário do que é utilizado } \\
\text { recorrentemente, na Fig. } 3 \text { o uso de } \\
\text { cores brilhantes na figura com } \\
\text { ênfase representada, neste caso, o } \\
\text { sonho do personagem. }\end{array}$ & $\begin{array}{l}\text { As cores das caixas de texto } \\
\text { possuem contraste com as } \\
\text { ilustrações. Contudo, seu } \\
\text { baixo nível de opacidade } \\
\text { dificulta a legibilidade dos } \\
\text { textos, prejudicando a } \\
\text { distinção entre eles e o } \\
\text { fundo (ilustração), } \\
\text { especialmente nas fontes } \\
\text { em branco, mesmo que seja } \\
\text { possível deslocar as caixas } \\
\text { de texto sobre o plano. }\end{array}$ \\
\hline $\begin{array}{l}\frac{0}{2} \\
\stackrel{2}{x} \\
\stackrel{+}{x}\end{array}$ & $\begin{array}{l}\text { As texturas utilizadas nas } \\
\text { figuras } 1 \text { e } 3 \text { (representando } \\
\text { mapas antigos e pergaminhos) } \\
\text { possuem qualidades visuais } \\
\text { semelhantes que expressam } \\
\text { unidade entre si e coerência } \\
\text { com o tema da narrativa } \\
\text { (busca ao tesouro). }\end{array}$ & $\begin{array}{l}\text { As texturas foram utilizadas com } \\
\text { ênfase no volume e no material por } \\
\text { meio de contrastes tonais das cores } \\
\text { - como a ilustração do espelho (Fig. } \\
\text { 2) e a roupa do personagem (Fig. } \\
\text { 1). }\end{array}$ & $\begin{array}{l}\text { Em algumas telas o } \\
\text { equilíbrio foi comprometido } \\
\text { pela variação de estilo de } \\
\text { texturas. Como a textura } \\
\text { naturalista do mar em } \\
\text { contraponto às texturas } \\
\text { expressivas da canoa e } \\
\text { outros elementos (Fig. } 3 \text { ). }\end{array}$ \\
\hline 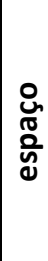 & $\begin{array}{l}\text { A distância entre essas caixas } \\
\text { de texto e a margem do plano } \\
\text { varia a cada tela, o que } \\
\text { compromete a unidade entre } \\
\text { as telas. }\end{array}$ & $\begin{array}{l}\text { Na Fig. } 2 \text { não existe espaço de } \\
\text { respiro, o que dificulta a percepção } \\
\text { dos elementos e a trajetória de } \\
\text { leitura, já que não existem pontos } \\
\text { de destaque. Já na Fig. } 4 \text { o espaço } \\
\text { de respiro implica em ênfase texto. }\end{array}$ & $\begin{array}{l}\text { Exceto na Fig. 2, os espaços } \\
\text { entre as formas estão } \\
\text { equilibrados. Já nas caixas } \\
\text { de textos, suas dimensões } \\
\text { fixas em relação ao texto } \\
\text { geram desequilíbrio (Fig. 3). }\end{array}$ \\
\hline
\end{tabular}




\begin{tabular}{|c|c|c|c|}
\hline$\frac{\stackrel{0}{\frac{\varepsilon}{2}}}{\frac{0}{3}}$ & $\begin{array}{l}\text { A representação de volume se } \\
\text { dá pelo tratamento de luz e } \\
\text { sombra. Também utiliza a } \\
\text { perspectiva, como podemos } \\
\text { identificar nas figuras } 2 \text { e } 3 \text {, } \\
\text { porém de forma mais sutil. }\end{array}$ & $\begin{array}{l}\text { A Fig. } 1 \text { se destaca por aplicar uma } \\
\text { sombra projetada do personagem } \\
\text { sobre o mapa. Já a Fig. } 4 \text { não } \\
\text { explora o volume, enfatizando a } \\
\text { interação como objetivo principal. }\end{array}$ & $\begin{array}{l}\text { A representação de volume } \\
\text { aplicada às caixas de texto, } \\
\text { gerada pelo tratamento de } \\
\text { luz e sombra, é fundamental } \\
\text { para a percepção de sua } \\
\text { posição em primeiro plano. }\end{array}$ \\
\hline
\end{tabular}

Fonte: Elaborado pelos autores, com base na pesquisa realizada.

A partir desta análise é possível identificar que a estrutura gráfico-visual do book app infantil Treasure Kai and the Lost Gold Shark Island foi planejada, em termos de definição e organização de seus elementos, com a aplicação de alguns princípios de design elencados por esta análise. De forma geral, apresenta uma solução gráfica rica na aplicação de recursos visuais e com uma boa integração entre estes e os demais recursos (texto, áudio e interatividade). Contudo, algumas das soluções aplicadas às telas deste ebook se mostraram mais adequadas do que outras.

Como ponto positivo destaca-se a integração entre texto escrito, áudio e imagem no mesmo plano, sem separação ou omissão, o que torna a interação mais fácil e interessante, sendo uma solução totalmente adequada a uma tela com as dimensões do dispositivo utilizado. Também a possibilidade de deslocar a caixa de texto sobre o plano, que explora o recurso de manipulação direta do dispositivo, permitindo que o usuário adeque o layout, de forma interativa, de acordo com sua preferência. Além da utilização do destaque das palavras do texto, sincronizadas com o áudio, favorecendo a leitura.

Por outro lado, percebem-se algumas questões que comprometeram a qualidade visual do livro como, por exemplo, a falta de consistência entre as telas gerada pela mudança de cor e deslocamento na posição das caixas de texto, bem como pela variação no destaque do texto sincronizado com o áudio (Fig. 2), visível nas telas. Da mesma forma que o uso de um número excessivo de formas na mesma imagem (Fig. 3), com o mesmo nível de detalhamento e mesmo tratamento de sombras e luzes, o que dificulta a percepção individual dos elementos, desvalorizandoos e ocultando suas qualidades interativas. Além de problemas de legibilidade devido ao baixo nível de opacidade das caixas de texto.

Somando-se a isso, a unificação do estilo aplicados às ilustrações . compromete a ênfase aos objetos interativos na interface visual, o que poderia ter sido explorado por meio de contrastes,. Neste caso, o princípio da força de percepção também foi prejudicado, pois em alguns momentos, principalmente na figura 3, o fluxo de narrativa pode ser interrompido para buscar padrões visuais que possam mostrar os objetos sonoros interativos ou simplesmente mudar a página.

\section{CONCLUSÃO}

Neste estudo foi possível perceber como a definição e a organização dos elementos gráfico-visuais bem como a aplicação de princípios de design podem influenciar na comunicação da mensagem visual e por consequência, na interação com o usuário. As soluções aplicadas ao design visual de interface de um ebook interferem na facilidade de leitura, na condução da narrativa e na motivação do usuário. Todos os aspectos da estrutura gráfico-visual atuam de forma integrada. Assim, uma solução equivocada pode comprometer todo o restante 
A análise do book app infantil Treasure Kai and the Lost Gold Shark Island permitiu identificar como soluções gráfico-visuais que contribuem para leitura interativa em ambiente digital: o uso de tratamento diferenciado para evidenciar os objetos interativos; mudanças de plano de fundo para indicar ou enfatizar as alterações de ambiente no fluxo da história; e o uso de contraste (cor, escala ou figurafundo) para facilitar a percepção dos objetos na interface, indicar hierarquia e ajudar na condução de uma leitura interativa, destacando objetos passíveis de interação.

Este estudo mostrou que a composição do espaço visual contribui para legibilidade e interação em uma interface visual digital. Isso pode ser alcançado de forma efetiva por meio de parâmetros de utilização dos elementos gráfico-visuais junto aos princípios de design, que contribuem com a leitura, orientando o fluxo narrativo e destacando os recursos de interatividade.

\section{REFERÊNCIAS}

Referências de Livro:

COSTELO, Vic et. al. Multimedia Foundations: core concepts for digital design. Waltham, MA - USA: Focal press/Elsevier, 2012.

CULLINAN, Bernice E. et al. Literature and the child. 8.ed. Belmont -USA: Wadsworth Cengage Learning, 2014.

DONDIS, Donis A.; CAMARGO, Jefferson Luiz. Sintaxe da linguagem visual. 2. ed. São Paulo: Martins fontes, 2003.

FARBIARZ, Alexandre. Entre o linear e o não linear do texto impresso ao eletrônico. In: FARBIARZ, Jackeline Lima; FARBIARZ, Alexandre; COELHO, Luiz Antônio L. (Org.). Os Lugares do Design na Leitura. Rio de Janeiro: Novas Idéias, 2008. P. 53-89.

GOMES FILHO, João. Gestalt do objeto. São Paulo: Escrituras editora, 2000.

LINDEN, Sophie Van der. Para ler o livro ilustrado. São Paulo: Cosac Naify, 2011.

LUPTON, Ellen; PHILLIPS, Jennifer Cole.Novos Fundamentos do Design. São Paulo: Cosac Naify, 2008.

Dissertações, teses, monografias e trabalhos acadêmicos:

a) Dissertação/Tese

SPALDING, Marcelo. Alice do livro impresso ao e-Book: adaptação de Alice no país das maravilhas de Através do espelho para iPad. Porto Alegre: UFRGS, 2012. 246 p. Tese (doutorado) - Programa de pós-graduação em letras, Faculdade de Letras, Universidade Federal do Rio Grande do Sul, Porto alegre, 2012.

Eventos:

CAMPOS, Amanda; SOUSA, Richard. A representação visual da moda nos suportes gráficos. In: CULTURA VISUAL, n. 18, dezembro/2012, Salvador: EDUFBA, P. 41-59.

NUNES, Juliane Vargas; GONÇALVES, Berenice Santos. Legibilidade e leiturabilidade em aplicativos para celular smartphone. In: INTERACTION SOUTH AMERICA 2013, 2013, RECIFE. Anais do 5o Congresso Internacional de Design de Interação, 2013. v. 1.

MeioEletrônico: 
Internet

BIRCHER, K. What makes a good picture book app? The Horn Book Magazine, p.72-78, março/abril, 2012. Disponível na internet por http em: <http://www.hbook.com/2012 /02/using-books/what-makes-a-good-picture-book-app/ >. Acesso em 16 fev. 2014.

DUARTE, Márcio. Ebook: desvendando os livros feitos de pixels. Brasília: PageLab, 2010. Disponível na internet por http em: <http://www.slideshare.net/marciom10>. Acesso em 15 março 2014.

PERASSI, Richard Luiz de Souza. Gramática comparada da representação gráfica. Convergências, Castelo Branco, v. 6, p.1-10, 30 nov. 2010. Semestral. Disponível na internet por http em: <http://convergencias.esart.ipcb.pt/artigo/92>. Acesso em 26 jan. 2013.

TEIXEIRA, Deglaucy Jorge et. al. Os códigos de linguagem como potencializadores da interação em aplicativos de literatura infantil: uma análise do app cinderella de nosy crow. In: 4o Congresso Internacional CBL do Livro Digital. São Paulo, 2013. Disponível na internet por http em: <http://www.congressodolivrodigital.com.br/site/ trabalhoscientificos>. Acesso em 12 fev. 2014. 